\title{
Determinação dos níveis de colesterol sérico em gatos (Felis catus) alimentados com ração deficiente em taurina
}

\section{Determination of the serum colesterol level in cats (Felis catus) Submited deficient ration in taurine}

\author{
Nádia Regina Pereira Almosny, ${ }^{*}$ João Marcelo Silva Silveira, ${ }^{\star \star}$ Leonardo Grain de Oliveira, ${ }^{* * *}$ Thereza Christina de \\ Vasconcelos, ${ }^{\star * \star *}$ Carmem Helena de Vasconcelos, ${ }^{\star \star \star \star \star}$ Anderson de Oliveira Monteiro ${ }^{\star \star \star \star \star \star}$
}

\begin{abstract}
Resumo
A deficiência de taurina tem sido descrita como sendo causadora de alterações metabólicas em gatos domésticos e estas são também descritas em casos de hipocolesterolemia. Analisaram-se, então, os níveis séricos de colesterol em cinco gatos submetidos, durante dois meses e meio, a rações deficientes em taurina e observou-se redução importante deste grupo em relação ao controle, concluindo-se que a deficiência de taurina não deve ser estudada como um fenômeno isolado na gênese de patologias.
\end{abstract}

Palavras-chave: gato; taurina; colesterol.

\section{Introdução}

A deficiência de taurina, aminoácido essencial para gatos, tem sido relacionada a vários estados patológicos. Tal aminoácido é importante na manutenção da permeabilidade de membranas biológicas, principalmente em tecidos excitáveis como o nervoso e o músculo cardíaco, exercendo também, segundo Burger \& Earle (1992), papel na osmorregulação e neuromodulação e como redutor de radicais livres.

A taurina, primeiramente associada à formação de ácidos biliares (juntamente com o colesterol), não faz parte de proteínas, existindo porém em grandes quantidades em todos os tecidos, principalmente no sistema nervoso central (Chandler et al., 1988 e Norworthy, 1993).

Nos felinos, a formação dos ácidos biliares ocorre através da conjugação com a taurina. No canino e no homem, a glicina é o principal aminoácido a formar estes ácidos, numa proporção de três partes para uma de taurina. No gato, a via preferencial é a que utiliza a taurina, aumentando bastante a necessidade deste aminoácido (Burger \& Earle, 1992).
Quando da deficiência de taurina em felinos domésticos, há degeneração central da retina, fracasso reprodutivo, cardiomiopatia dilatada, leucopenia, além de outras complicações (Burger \& Earle, 1992). Entretanto, alterações nos níveis de colesterol séricos estão também associados a sintomas neurológicos, incluindo alterações cerebelares e desmielinização, distúrbios visuais, alterações cardíacas, eritrocitárias, reprodutivas e na permeabilidade de membranas biológicas (Gilman et al., 1987 ; Bevilacqua et al. 1989 \& Murray et al., 1994).

O objetivo deste experimento foi avaliar os níveis de colesterol séricos em gatos, submetidos a dietas deficientes em taurina devido à íntima relação metabólica entre estes dois elementos e aos escassos estudos referentes a este lipídio em felinos.

\section{Material e método}

O grupo experimental constou de quatro gatos sem raça definida de ambos os sexos, com três meses de idade e o grupo-controle, de cinco gatos com idade variando de três

\footnotetext{
* Médico Veterinário, MsC, Prof. adjunto do Dep. de Patologia e Clínica Veterinária (UFF). almosny@urbi.com.br. (Autor para correspondência). ** Médico Veterinário, Prof. substituto do Dep. de Patologia e Clínica Veterinária (UFF). Aluno do curso de Mestrado em Med. Veterinária da UFF. 
meses a dois anos. Todos os animais foram vermifugados ${ }^{1} \mathrm{e}$ o grupo experimental foi mantido durante dois meses e meio em gaiolas, onde receberam alimentação à base de cereais, acrescido de vitamina $A$ e água. Este grupo era exercitado diariamente e tomava banho de sol regularmente.

O grupo-controle também foi mantido em gaiolas, recebendo carne bovina, peixe e ração para gatos. ${ }^{2}$

Coletaram-se amostras de sangue para determinação dos níveis de colesterol, através de venipunção jugular, utilizando-se seringa e agulha. $O$ sangue era colocado em tubos de hemólise e após a coagulação e retração do coágulo, procedia-se a separaçãó do soro através de centrifugação. A colesterolemia foi avaliada por espectrofotometria utilizando-se kit comercial. $^{3}$

\section{Resultados e discussão}

Os níveis de colesterol séricos nos animais-controle variaram de 103 a $150 \mathrm{mg} \%$, enquanto que nos cinco animais submetidos à dieta deficiente em taurina, os níveis de colesterol estiveram entre 35 e $52 \mathrm{mg} / \mathrm{dl}$. (32, 44, 46, 46 e $52 \mathrm{mg} / \mathrm{dl})$.

Houve redução significativa nos níveis de colesterol séricos nos animais submetidos à alimentação deficiente em taurina, ao contrário dos que receberam alimentação adequada. Estes dados estão de acordo com os de Fox et al. (1993) que relataram um decréscimo de $36 \%$ nos níveis de colesterol em animais portadores de níveis deficientes de taurina.

O colesterol tem sido, freqüentemente, associado a patologias decorrentes de sua elevação plasmática (Stryer, 1993). Entretanto, este mesmo elemento é imprescindível à vida animal, sendo importante modulador da fluidez das membranas eucariontes, precursor dos hormônios esteróides, sais biliares, e vitamina D (Buffington,1994).

Pesquisas referentes a deficiência nos níveis de taurina em gatos, realizados por Burger \& Earle (1992), Royer \& Durbille (1992) e vasta literatura revelaram quadros mórbidos relacionados às alterações em membranas biológicas, lesões oculares, alterações neurológicas, reprodutivas cardíacas e em células de defesa. No presente estudo, observou-se acentuada redução nos níveis de colesterol séricos nos animais com deficiência de taurina. Estudos relacionados à hipocolesterolemia no homem, relatados por Gilman et al. (1987), Bevilacqua et al. (1989), Stryer (1993) e Murray et al. (1994), descreveram a ocorrência de neuropatias periféricas e cerebelares, alterações auditivas e visuais, cardíacas e reprodutivas, alterações estas, extremamente semelhantes às decorrentes da redução dos níveis de taurina em gatos e, por isto, correlacionadas ao presente estudo.

Os ácidos biliares são a principal via de excreção do colesterol e também um elemento-chave na absorção de lipídios, por sua capacidade de aumentar a permeabilidade das membranas e, com isto, facilitar o intercâmbio de íons Burger \& Earle (1992).

Segundo Gilman et al. (1987), Murray et al. (1994) e Burtis \& Ashwood (1994), os sais biliares exercem um papel regulador na excreção do colesterol, pois, quanto menos ácidos biliares forem reabsorvidos, mais colesterol é desviado para a formação destes.

Neste experimento, os animais privados de quantidade adequada de taurina não formaram ácidos biliares em quantidade suficiente e o colesterol foi desviado para a formação de mais colato, que é o precursor do ácido taurocólico. Porém, não havia taurina suficiente para a sua conjugação. O colato liberado para o intestino possui baixa capacidade de reabsorção sem a presença de taurina, sendo, então, excretado nas fezes, o colesterol sérico é desviado para a formação de mais precursor, formando um ciclo vicioso que determina a hipocolesterolemia.

Este mecanismo é justificado pela ação dos medicamentos formadores de complexos inabsorvíveis com os sais biliares que visam a redução dos níveis de colesterol séricos descritos por Gilman (1987) e por relatos de Fox et al. (1993) que também observaram hipocolesterolemia em gatos deficientes em taurina.

Conclui-se no presente estudo que a redução dos níveis de taurina, citados por Chandler et al. (1988), e Burger \& Earle (1992) e Norworthy (1993) e vasta literatura, prejudicaria a regulação do potencial de membrana, com prejuízo para a saúde do gato, porém não ocorreria como um fenômeno único na gênese das patologias, devendo-se considerar as conseqüências da hipocolesterolemia que agravaria bastante os sintomas decorrentes da deficiência do aminoácido.

\section{Conclusões}

Houve redução significativa dos níveis de colesterol séricos nos gatos submetidos à ração deficiente em taurina.

Devido às alterações decorrentes de hipocolesterolemia serem semelhantes às que ocorrem em animais deficientes em taurina são necessários estudos complementares, correlacionando as duas patologias.

Estudos referentes às lipoproteínas deverão ser efetuados a fim de um maior aprofundamento.

\footnotetext{
${ }_{1}^{1}$ Necamim - Laboratório Aché; ${ }^{2}$ Whiskas - Effem - Br 116 Km 286 Eldorado do Sul - RS - Brasil; ${ }^{3}$ Kits Labtest.
} 


\begin{abstract}
Cholesterol levels were determined in cats fed with a deficient ration program during two months. In this program the taurine was retired from the ration. The reduction in the cholesterol level was significative. In conclusion, the taurine deficience must not be studied as a isolated phenomenon in the pathology genesis.
\end{abstract}

Keywords: cat; taurine; cholesterol.

\section{Referências bibliográficas}

BEVILACQUA, E., BENSOUSSAN, E., JANSEN, J.M., etal. Fisiopatologia Clínica 4. ed. Rio de Janeiro: Atheneu, 1989. 701 p.

BURGER, I., EARLE, K. Taurina. Waltham Int. Foc., v. 2, n. 2, p. 9-13, 1992.

BUFFINGTON, T. Nutritional diseases and nutritional therapy. In: SHERDING, R.G. The cat diseases and clinical management. 2. ed. New York : Churchill Livingstone, 1994. p. $161-190$.

BURTIS, C.A \& ASHWOOD, E.R. Tietz Textbook of clinical Chemistry. 2. ed. Philadelphia. W.B. Saunders Company. 1994. $2326 \mathrm{p}$.

CHANDLER, E.A., HILBERY, A.D.R., GASRELL, C.J. Medicina e Terapêutica de felinos. 2.ed. São Paulo : Manole, 1988. p. 447.

FOX, P.R, TRAUTWEIN, E.A, HAYES, K.C, BOND, B.R, SISSON, D.D; MOISE,N.S. Comparison of taurine, alpha tocoferol, retinol, retinol, selenium, total triglycerides and cholesterol concentrations in cats with cardiac disease and in health cats. Am. J. Vet. Apr; v. 54, n. 4, p. 563-569, 1993.

GILMAN, A.G., GOODMAN, L.S., RALL, T.N., et al. As Bases Farmacológicas da Terapêutica. 7. ed. Rio de Janeiro : Guanabara Koogan, 1987. p. 1195.

MURRAY, R.R., GRANNER, K.K., HAYES, P.A., et al. Bioquímica. 7. ed. São Paulo: Atheneu, 1994, p. 763.

NORWORTHY,G.D. Feline Practice. Philaderphia. J.B. Lippincott Company. 1993. 688 p.

ROYER, D, DURBILLE, A. Les acides beleaires le chiem et. du chat. Prat. Med. et Chirurg de d'animal de Conpagnie. v. 27, n. 6, p. 805-810, 1992.

STEIN, E.A., MYERS, G.L. Lipids, lipoproteins and apolipoproteins. In: BURTIS, C.A., ASHWOOD, E.R. Clinical Chemistry. 2. ed. Philadelphia : W.B. Saunders Company, 1994, p. 1002-1081.

STRYER, L. Bioquímica. 3. ed. Rio de Janeiro : Guanabarra Koogan, 1993, p. 881. 